\title{
Nodulation and Symbiotic Nitrogen Fixation in the Biofuel Legume Tree Pongamia pinnata
}

\author{
Phoebe Nemenzo-Calica ${ }^{1,2}$, Arief Indrasumunar ${ }^{1,2}$, Paul Scott ${ }^{1,2}$, Peter Dart ${ }^{2}$, and Peter M. \\ Gresshoff ${ }^{1,2^{*}}$
}

1 Centre for Integrative Legume Research; ${ }^{2}$ School of Agriculture and Food Sciences, The University of Queensland, St Lucia, Brisbane QLD 4072, Australia

Received: August 15, 2016 / Accepted: September 9, 2016

\begin{abstract}
The legume tree Pongamia pinnata (also called Millettia pinnata) is a non-food crop that can grow on marginal land not destined for the cultivation of food crops. It is an important candidate for the production of biofuel (bio-oil, biodiesel and aviation biofuel) from its oil-rich seeds. An important trait is its ability to grow in marginal, nitrogen-limited soils. This growth ability is attributed to the nitrogen-fixation activity of root nodules. Cutting both cotyledons in halves had little effect on shoot dry weight, nodule number and weight per plant at 8 weeks. These parameters were reduced when both cotyledons were removed; plants were visibly yellow. Surprisingly when no nutrients were supplied and with both cotyledons intact, plants grew as well as those with nutrients. To isolate rhizobial inoculants from soil, samples were collected from Meandu Mine, a coal-mining site near Kingaroy, Queensland (Australia), where pongamia is currently grown to rehabilitate the soil. Pongamia nodules were also collected from Mt. Coot-tha Botanic Gardens (Brisbane), where pongamia was introduced decades ago. Established 'Baiting technique' and 'One-drop-one-nodule technique' were applied to isolate potential rhizobia from the soil samples and nodules. All isolates were screened and characterised for symbiotic effectiveness and nitrogenase activity. A total of 21 putative rhizobial samples were isolated - five from soil samples and 16 from pongamia nodules. Out of these iso
\end{abstract}

lates, seven were slow-growers while 14 were fast-growers. These isolates were coded as PR-UQ. Among the isolates, the fast-growers PR-UQ-03 and PR-UQ-05 were considered as the superior strains compared to the slow-growers PR-UQ-01 and PR-UQ-04, which were more effective than the rest of the isolates. The new isolates enhanced nodule number, shoot length and total plant dry weight and resulted in better plant growth than the available Bradyrhizobium japonicum strains CB1809, USDA110 and CB564. Acetylene reduction assay (short term) and Nitrogen Difference Analysis (long term) further confirmed that pongamia fixed more nitrogen upon inoculation with these rhizobia. Based on 165 rDNA sequence analysis, PR-UQ-01 and PR-UQ-04 are closely related to Bradyrhizobium elkanii and Bradyrhizobium pachyrizi, while PR-UQ-03 and PR-UQ-05 are both related to Rhizobium mesoamericanum. Cotyledons supply the seedling with nutrients for a considerable period of early seedling growth. The newly isolated, fast-growing rhizobia PR-UQ-03 and PRUQ-05 and the slow-growing PR-UQ-01 and PR-UQ-04 are related to Rhizobium and Bradyrhizobium species and aid in the nodulation, nitrogen fixation and seedling/sapling growth of Pongamia pinnata.

Keywords: Biofuel, Bradyrhizobium, Nodulation, Nitrogen Fixation, Rhizobium, 16S rDNA.

* Corresponding author: p.gresshoff@uq.edu.au

This is an Open Access article distributed under the terms of the Creative Commons Attribution License (http://creativecommons.org/licenses/by/3.0/), which permits unrestricted use, distribution, and reproduction in any medium, provided the original work is properly cited. 


\section{Introduction}

Pongamia pinnata, a fast growing, outcrossing, papillionaceous tree legume with high oil content seeds found in northern Australia, Papua New Guinea, Indonesia and India, is a potential feedstock for biofuel production (Biswas et al., 2013; Gresshoff et al., 2015; Scott et al., 2008). It is salinity and drought tolerant (especially when established beyond the seedling stage), and grows well in low fertility soils (Kazakoff et al., 2011). This legume tree produces seeds, which contain about $40 \%(\mathrm{w} / \mathrm{w})$ oil, predominantly $50 \%$ of which is the mono-unsaturated oleic acid (C18:1) that can be used for biodiesel production (after transesterification with methanol or ethanol; Kazakoff et al. $2011)$. The oil is low in saturated palmitic (C16:0) and stearic (C18:0) acids, and is non-edible. Following oil extraction the resultant seedcake finds utility as supplemental animal feed for poultry, cattle and sheep, though only in small portions (10-20\% of total feed; (Biswas and Gresshoff, 2014; Chandrasekaran et al., 1989; Konwar, 1987a, 1984, 1987b, c; Natanam et al., 1989a; Natanam et al., 1989b; Natanam et al., 1989c; Natanam, 1989; Ravi et al., 2000; Singh et al., 2006).

Multiple pod components (including the oil, seed cake, and pod walls) can be used for energy production via co-combustion, or fermentation. Pongamia oil is made up predominantly of triglycerides, which can be converted by transesterification to biodiesel (fatty acid methyl esters; FAME) or by hydrogenation to aviation A1 jet fuel (Kazakoff et al., 2011 ; Klein-Marcuschamer et al., 2013).

The potential of pongamia as a biofuel feedstock is now acknowledged (Dwivedi et al., 2011 ; Kazakoff et al., 2012; Kesari and Rangan, 2010; Klein-Marcuschamer et al., 2013; Murphy et al., 2012; Naik et al., 2008; Samuel et al., 2013). According to the US Department of Energy (International Energy Outlook 2009), the current demand for oil from fossil fuels is around 85 million barrels per day (approximately 13.5 billion litres). In 2030 , it is expected that oil demand will be around 106 million barrels per day (approximately 16.9 billion litres). Pongamia and other biofuel feedstocks can contribute substantially to the future energy demands of the domestic and industrial economies. Pongamia is a strong candidate as a biofuel because it meets two criteria as an effective, second-generation biofuel, namely (1) it must be a non-food crop that can grow on marginal land not used for the cultivation of food crops, and (2) the use of vegetable oils from plants must provide an environmentally acceptable fuel, the production of which is greenhouse gas neutral, with reductions in current diesel engine emissions. Moreover, the composition of seed oil and the properties of fatty acid methyl esters (FAMEs) of pongamia meet both North American and European industry standards (Scott et al., 2008).

Pongamia is yet to undergo any directed domestication that has accompanied the development of other modern annual and perennial crops. Some selection for yield and tree architecture may have occurred in India over the thousands of years of 'village' agriculture. There is no published record of breeding programs for pongamia. To initiate a directed domestication program, desirable traits need to be defined in concert with functional genomics studies to identify and characterise the rel- evant traits. The suggested domestication traits include nitrogen fixation efficiency, which is deemed as highly important, as it relates to the environmental and economic costs of nitrogen fertiliser supplementation. Other suggested traits include repeated annual cropping, crop uniformity, seed mass per tree (yield), extractable seed oil content, oil composition and stability, growth vigour at seedling and adult stage, erect growth and architecture, canopy density, seed abscission, resistance to insects, nematodes, fungi and bacteria, flowering time, water-use efficiency, hardiness to cold, acid soils, drought and salinity. Many of these traits will be multigenically controlled and breeding will be an on-going task for the emerging pongamia biofuel industry.

Pongamia nodulates well with a wide range of strains including Bradyrhizobium and Rhizobium such as Bradyrhizobium sp. strain CB564 and Rhizobia sp. strain NGR234 (Pueppke and Broughton, 1999; Rasul et al., 2012; Scott et al., 2008), Bradyrhizobium japonicum CB 1809 and USDA 110 (both slow growing rhizobia and widely used commercial inoculants for soybean) as well as fast growing rhizobia (Arpiwi et al., 2012; Samuel et al., 2013). Some reports indicate that trees, including pongamia, are mainly nodulated by fast-growing rhizobia than by slow-growing rhizobia (Moreira et al., 2006). However, the geographic and soil type distribution and taxonomy of rhizobia strains capable of nodulating pongamia and their effectiveness in symbiotic nitrogen fixation are little understood.

An indirect technique to isolate rhizobia from soil is to use an uninoculated host plant as 'bait' in sample soils and then later on isolate putative inoculant from the surface-sterilised nodule. This baiting technique, which uses nodules as effective traps for selective enrichment, allows isolation of rhizobia classified in different cross-inoculation groups (Gault and Schwinghamer, 1993). In a study by Rasul et al. (2012), 29 rhizobia strains were isolated by planting sterilised pongamia seedlings into soils collected from Andhra Pradesh, Maharashtra and Karnataka in Southern India. The ability of these strains to fix nitrogen was not assessed and there was no superior isolate identified in this study, although evaluation of nodulation and molecular analysis were conducted on these rhizobia. Another baiting experiment was conducted in Western Australia in which 40 strains were isolated from soil samples (Arpiwi et al. 2012). In this study, the superior rhizobia strain was determined as Bradyrhizobium yuanmingense. All rhizobia strains from both of these studies were able to form 'creamy or white opaque' colonies on growth media with Congo Red, which is a characteristic of all rhizobia.

On the basis of phenotypic, phylogenetic distinctiveness and molecular data, a novel species of the genus Rhizobium, Rhizobium pongamiae was isolated from nodules of pongamia in North Guwahati, Assam, India (Kesari et al., 2013). It is a gramnegative, non-motile, fast-growing, rod-shaped bacterium, which grew optimal at $28^{\circ} \mathrm{C}$, pH 7.0 and in medium supplemented with $2 \% \mathrm{NaCl}$. It exhibits higher tolerance to the prevailing adverse conditions, for example, salt stress, elevated temperatures and alkalinity and was found to fix nitrogen using the acetylene reduction assay. PCR detected a nifH gene, encoding the iron component of nitrogenase (Kesari et al., 2013).

In the symbiotic relationship with host legumes, rhizobia can promote the host plants' growth by providing available nitrogen, 
which would normally be restricted to them. Therefore, isolation, characterisation and selection of suitable rhizobia strains must be conducted to promote the growth of pongamia and increase its potential yields. This study aimed to identify effective rhizobia that can nodulate and fix nitrogen with pongamia in Queensland, Australia.

\section{Materials and Methods}

\section{Cotyledon Nutrient Carry-Over}

To determine the role of cotyledons in nodulation and avoid the carry-over of nutrients from cotyledons, 40 pongamia seedlings growing in sterile vermiculite at 20 days old were divided into five treatments: (1) inoculated with CB 1809 but no nutrient solution added; (2) uninoculated and no nutrient solution added; (3) inoculated with CB1809 with nutrient solution (B\&D N-free solution); (4) uninoculated but with nutrient solution; and, (5) uninoculated but with nitrogen ( $2 \mathrm{mM}$ ammonium nitrate solution) and nutrient solution. Two replicates per treatment were used. Their cotyledons were either cut, removed, or left intact as soon as primary leaves uncurl; all of the seedlings for each treatment were coded as: OCOT $=$ Both cotyledons were removed; 1COT = One cotyledon removed; 2COT = Both cotyledons intact; $1 / 2$ COT $=$ Both cotyledons cut into halves. After eight weeks, the plants were uprooted and nodulation was assessed.

\section{Isolation of Rhizobia}

The soil samples were characterised by $\mathrm{pH}$ and nutrient component analysis. To get the $\mathrm{pH}$ of the soil samples, samples were air-dried and homogenised to $<1 \mathrm{~mm}$ diameter. Six grams of each sample were weighed and put inside a 50-ml Falcon tube. Two replicates were made for each sample. Then, $30 \mathrm{ml}$ of deionised water was added into each tube (1:5 soil solution ratio). The soil samples were mixed for an hour on an end-overend shaker at room temperature. The $\mathrm{pH}$ was then measured using the $\mathrm{pH}$ meter by directly dipping the $\mathrm{pH}$ electrode into each tube. For total Carbon and Nitrogen level analysis, dried samples were subjected to combustion and analysed using a LECO TruSpec analyser. For total nutrient analysis, samples were extracted and analysed using a Varian Vista Pro ICPOES instrument.

Baiting technique was employed to isolate the rhizobia from soil samples from the Meandu Mine (six different sites). Soil samples were filled into sterile pots. Pongamia seeds were sizesorted and weighed to select the best seeds, surface-sterilised with $5 \%$ commercial bleach for one minute and rinsed with $70 \%$ ethanol twice followed by washing seven times sterile distilled water, after imbibition and sown directly into the soil. Plants were maintained in the glasshouse at $27-30^{\circ} \mathrm{C}$ daytime and 17 $20^{\circ} \mathrm{C}$ night time temperature during summer season and watered with 100-ml B\&D nutrient solution (stored at room temperature) once and $100-\mathrm{ml}$ sterile distilled water afterwards as needed. Plants were protected from cross-contamination by covering the surface with white sterile beads with a pipe inserted for watering purposes. The plants were uprooted after 10 weeks. Larger, pink nodules that were close to the crown or primary roots were selected for the isolation of rhizobia in the laboratory. Data were gathered for shoot length, number of nodes, number of leaflets, number of nodules, root, shoot, nodule and total plant dry weights, nodule fresh weight (preserved), soil type and properties, soil analysis and nodule morphology.

To isolate rhizobia from the pongamia nodules collected from Mt. Coot-tha (Brisbane, Queensland) and from the nodules produced from baited plants in soil samples, the one-drop-onenodule technique was employed, in which five nodules (large and pink inside) per replicate plant were selected, placed inside sterile tubes and then surface-sterilised with $95 \%$ ethanol for 5 seconds and 3\% commercial bleach for 5 minutes. Each nodule was crushed into a drop of sterile distilled water in an empty sterile Petri dish using sterile forceps. The nodule extract was then streaked three-ways into the yeast extract mannitol agar with Congo Red (YEMA+CR). Plates were incubated for 6-10 days at $28^{\circ} \mathrm{C}$. Well-isolated colonies that appeared on plates after 3-5 days of incubation were sub-streaked into another yeast extract mannitol agar plate and were designated as "fast-growers", while colonies that grew within 6-10 days of incubation were designated as "slow-growers". All isolates were purified by serial sub-streaking into YEMA+CR until pure cultures (judged by consistent colony morphology) were achieved.

\section{Nodulation and Symbiotic Effectiveness Under Glasshouse Condi- tions}

The rhizobia that produced the highest number of 'active' nodules in pongamia were determined based on the assessment of nodulation and symbiotic effectiveness tests. Pure cultures of the isolates and the three available rhizobia strains in the laboratory known to nodulate soybeans (i.e., CB1809, USDA 110 and CB564) were inoculated into YMB for 48 hours with shaking. The culture suspensions were then inoculated into surface-sterilised pongamia sown in sterile vermiculite in $15 \mathrm{~cm}$ pots which were thinned out later into one plant per pot. Five replicate plants were done for each treatment. Plants were maintained under glasshouse conditions, watered with $\mathrm{N}$-free nutrient solution (B\&D nutrient solution) and sterile distilled water and were harvested after 12 weeks. Surfaces of the pots were covered with sterile white beads, in which a pipe was used as opening for watering purposes. The holes of the pipes were covered with sterile aluminium foil to prevent cross-contamination. The data gathered include: shoot length, number of nodes, number of leaflets, number of nodules, root, shoot, nodule and total plant dry weights, nodule fresh weight (preserved), and nodule morphology.

All data were statistically analysed and the symbiotic effectiveness was computed using the formula (Bergersen, 1988):

\section{Symbiotic Effectiveness $=\frac{\text { Dry weight (Inoculated) } \times 100}{\text { Dry weight (Uninoculated) }}$}




\section{Time Course of Nodulation}

Surface-sterilised seeds were sown into sterile vermiculite and inoculated with the best rhizobia isolates. An uninoculated control was also included. Five replicates were used per treatment and the plants were uprooted at 4 to 8 weeks for data collection: nodule number, nodule fresh weight, shoot and root dry weights, total $\mathrm{N}$ level in dried shoots and roots, area of zone of infection using a dissecting microscope attached to NIS-Elements software program for image analysis and leghemoglobin concentration using spectrophotometry (Bio-Rad SmartSpec ${ }^{\text {TM }} 3000$ spectrophotometer, USA, 2014).

\section{Assessment of Symbiotic Nitrogen Fixation}

Plants inoculated with the best isolates were subjected to Acetylene Reduction Assay (ARA) to assess the nitrogen fixation activity in the nodulated roots and compared to soybeans. The root system was carefully shaken to remove the vermiculite and were cut and quickly transferred into sealed bottle containers with Suba-seals (Sigma-Aldrich, Australia). The 10\% of total gas volume was removed and replaced with $10 \%$ acetylene. At 0 and 60 minutes, the gas samples were obtained by a syringe and were directly assayed to Gas Chromatography (injected into a Shimadzu GC-17A gas chromatograph (FID detector, 2 $\mathrm{m}$ self-packed PoraPak $\mathrm{N} 60$ column) set with a column oven temperature as $90{ }^{\circ} \mathrm{C}$, detector and injection chamber at 110 ${ }^{\circ} \mathrm{C}$ and gas pressure $90 \mathrm{kPa}$.). The short assay time was used to avoid root cutting associated drop of measurable ARA. Meanwhile, the Nitrogen Difference method was also employed to estimate the amount of fixed nitrogen in all dried plants inoculated with rhiziobia and the reference treatments.

\section{Characterisation of Rhizobia}

The isolates were morphologically characterised based on their colony size in diameter, colour, shape, margin, elevation and texture. Growth curves in liquid culture of all isolates were also determined. One millilitre of pure culture was inoculated to 99 $\mathrm{ml}$ of yeast extract mannitol broth and incubated with shaking at $28^{\circ} \mathrm{C}$. At $0,18,24,45,48,68$ and 72 -hour incubation, 0.1 $\mathrm{ml}$ of the culture suspension was diluted to $10-6$ to $10-8$ using sterile dilution blanks and plated on YM agar at $28^{\circ} \mathrm{C}$. Viable count was determined after 5-10 days of incubation. Growth curves were plotted based on the viable count for each incubation time. The antibiotic resistance of each isolate was also determined. Isolates were grown in YM broth (YMB) with shaking until the titre of about 108 cells $/ \mathrm{ml}$ was achieved. A dilution of 10-6 was made and then plated into YEMA+CR containing different antibiotics. After 6-12 days at $28^{\circ} \mathrm{C}$, viable count of the isolates was determined implicating their antibiotic resistance or sensitivity, while their morphological characteristics on the media with antibiotics were also noted. The isolates were also grown in various growth conditions to determine their tolerance in different temperature $\left(22^{\circ} \mathrm{C}, 37^{\circ} \mathrm{C}\right.$ and $\left.45^{\circ} \mathrm{C}\right), \mathrm{pH}(4.0,7.0$ and 9.0), and salinity $(0.1 \%, 0.5 \%$ and $1 \%(\mathrm{w} / \mathrm{v}) \mathrm{NaCl})$.

\section{Identification of the Rhizobia Strains}

Rhizobia were grown in YMB in flasks and then transferred into $1.5 \mathrm{ml}$ centrifuge tubes. Tubes were centrifuged at 16,000 $\mathrm{g}$ for $10 \mathrm{~min}$ (using an Eppendorf centrifuge 5415D, F45-24-11, Germany). The resulting supernatant was decanted. The rhizobia were resuspended in $467 \mu \mathrm{l}$ of $10 \mathrm{mmol} / \mathrm{L}$ Tris- $\mathrm{HCl}, \mathrm{pH} 8$ and $1 \mathrm{mmol} / \mathrm{L}$ EDTA. Then $30 \mu \mathrm{l}$ of $10 \%$ SDS and $3 \mu \mathrm{l}$ of 20 $\mathrm{mg} / \mathrm{ml}$ proteinase $\mathrm{K}$ was added into the tubes.

Tubes were incubated for 1 hour at $37^{\circ} \mathrm{C}$. Phenol:chloroform :isoamylalcohol $(25: 24: 1 ; 500 \mu \mathrm{l})$ was added. Tubes were centrifuged in an Eppendorf centrifuge (5415 D) at 16,000 $\mathrm{g}$ for $2 \mathrm{~min}$. Sodium acetate $(3 \mathrm{M}, 0.1 \mathrm{ml}, \mathrm{pH} \mathrm{5.2)}$ and $0.6 \mathrm{ml}$ of isopropanol were added to precipitate the DNA. Tubes were incubated at least 30 minutes on ice. The tubes were centrifuged in an Eppendorf centrifuge (5415 D) for 15 minutes at 16,000 g. The DNA pellet was washed in $500 \mu \mathrm{l}$ of $70 \%$ ethanol. The tubes were centrifuged again for 15 minutes. The DNA was dried and resuspended in $100 \mu \mathrm{l}$ of sterile MilliQ water.

A total of $100 \mu \mathrm{l}$ of PCR cocktail was used with the following recipe: $200 \mu \mathrm{M}$ each of dATP, dCTP, dGTP and dTTP; 0.4 $\mu M$ of each universal primer 27F: GAGTTTGATCCTGGCTCAG (Dorsch and Stackebrandt, 1992) and 1492R: TACGGTTACCTTGTTACGACTT (Goodfellow and Stackebrandt, 1991); 1 x DNA polymerase and 50-500 ng of template DNA and covered with $50 \mu \mathrm{l}$ of sterile mineral oil. The PCR profile used was initial denaturation at $94^{\circ} \mathrm{C}$ for $2 \mathrm{~min}$; denaturation at $94^{\circ} \mathrm{C}$ for $1 \mathrm{~min}$ at 40 cycles; annealing at $52^{\circ} \mathrm{C}$ for 30 seconds; extension at $72^{\circ} \mathrm{C}$ for 30 seconds and final extension for $2 \mathrm{~min}$.

Five $\mu$ l of each of the PCR products were loaded to the wells of a $1 \%$ agarose gel with $2 \mu \mathrm{l}$ loading dye along with a $1 \mathrm{~kb}$ molecular ladder. The resulting molecular bands were isolated from the gel and sent to AGRF (Brisbane) for DNA sequencing and identification. The sequences were aligned using MUSCLE 3.8.31 and refined using Gblocks $0.91 \mathrm{~b}$. The phylogeny was run using PhyML 3.1/3.0 aLRT and rendered using TreeDyn 198.3 (Dereeper et al., 2008).

\section{Results}

\section{Cotyledon Nutrient Carry-Over}

All of the uninoculated treatments did not produce nodules. For the treatments without $\mathrm{N}$-free nutrient solution added, either inoculated with CB1809 or not, the data between replicates had higher variation while replicates for treatments watered with nutrient solution had closer values. Treatment with ammonium nitrate and with both cotyledons cut in halves had the longest average shoot length of $52 \mathrm{~cm}$, while the same treatment but with intact cotyledons had the most number of nodes and leaflets, with mean values of about 8 and 16, respectively. See supplemental Table S1.

Figure 1 shows the nodulation assessment of all the treatments which revealed that the highest number of nodules was observed in the inoculated treatments added with nutrient solution and with both cotyledons intact. Both inoculated treatments were able to produce several nodules but higher number was 


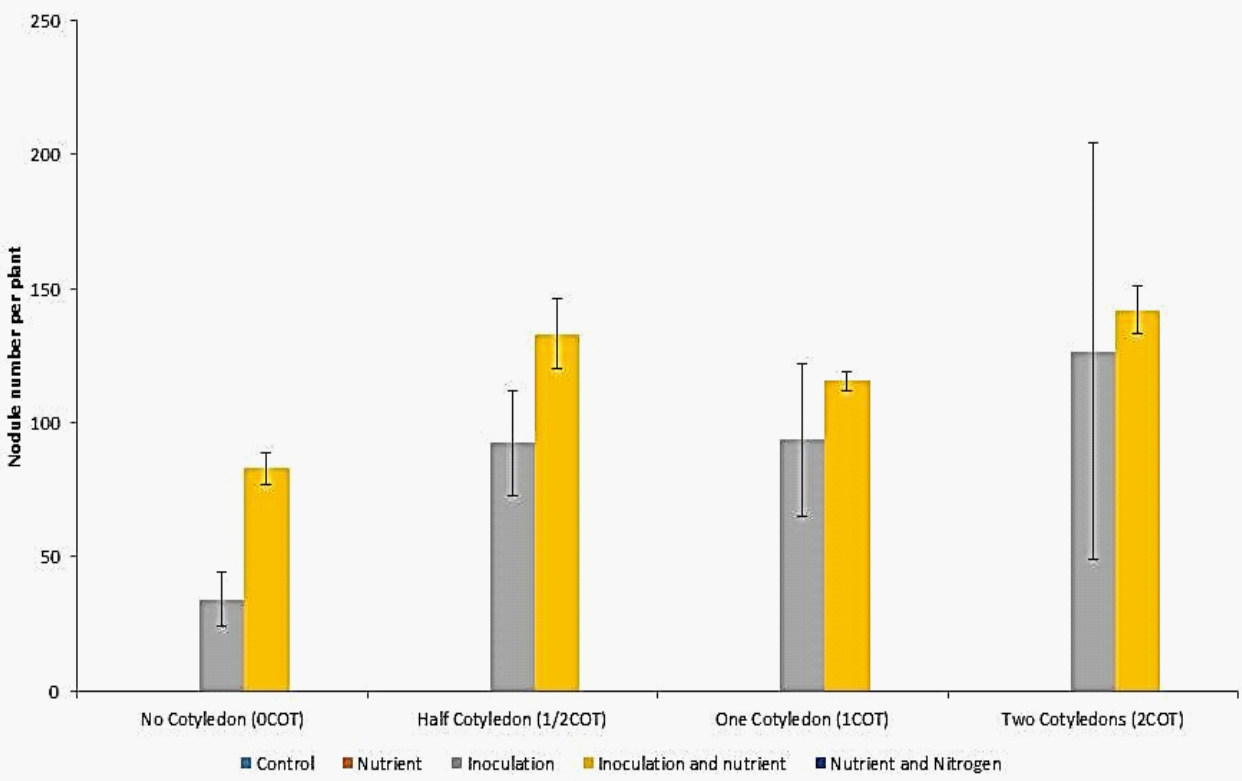

Figure 1. Nodule number vs the five different treatments: inoculated with $C B 1809$ but no nutrient solution added; uninoculated and no nutrient solution added; inoculated with CB1809 with nutrient solution (B\&D N-free solution); uninoculated but with nutrient solution; and, uninoculated but with nitrogen ( $2 \mathrm{mM}$ ammonium nitrate solution) and nutrient solution.

observed in the treatments with nutrient solution.

There were also no huge differences in the plant structure, nodulation and growth conditions among treatment plants with intact cotyledons, one cotyledon removed and both cotyledons cut into halves. See supplemental Figure S1. Treatment plants with ammonium nitrate had the best growth and health conditions as evidenced by their dark green shoots. Uninoculated plants without both cotyledons were able to survive after 16 weeks and showed differences from the rest of the treatments, as they had the poorest plant growth and symbiosis parameters, such as the lowest number of nodes, leaflets, shoot height, nodule number, fresh and dry nodule weight, and shoot and root dry weights. The appearance of visible difference in growth conditions among the inoculated, uninoculated, with or without nutrient solution and with nitrogen treatment plants had been obvious earlier in plants with both cotyledons halved. Growth variations were noted in just 3-4 weeks after inoculation while variations for other plants (either both cotyledons intact, one removed or both cotyledons removed), were observed at later stages of around 7-8 weeks after inoculation or at harvesting.

\section{Isolation of Rhizobia}

A total of 21 potential rhizobia were successfully isolated from the different soil samples and pongamia nodules collected in Queensland, Australia (see supplemental Table S2). Meanwhile, Supplemental Table S3 shows the results of soil analysis for each soil sample. Soil 1 and 3 were sandy while the rest were loamy. Soil 1 (shale/sandstone) had the highest $\mathrm{N}$ level of $0.062 \%$ wt, while Soil 2 (Farmhouse Control Site) had the lowest $\mathrm{N}$ level of $0.497 \%$ wt. Only Soil 1 had a neutral pH while the

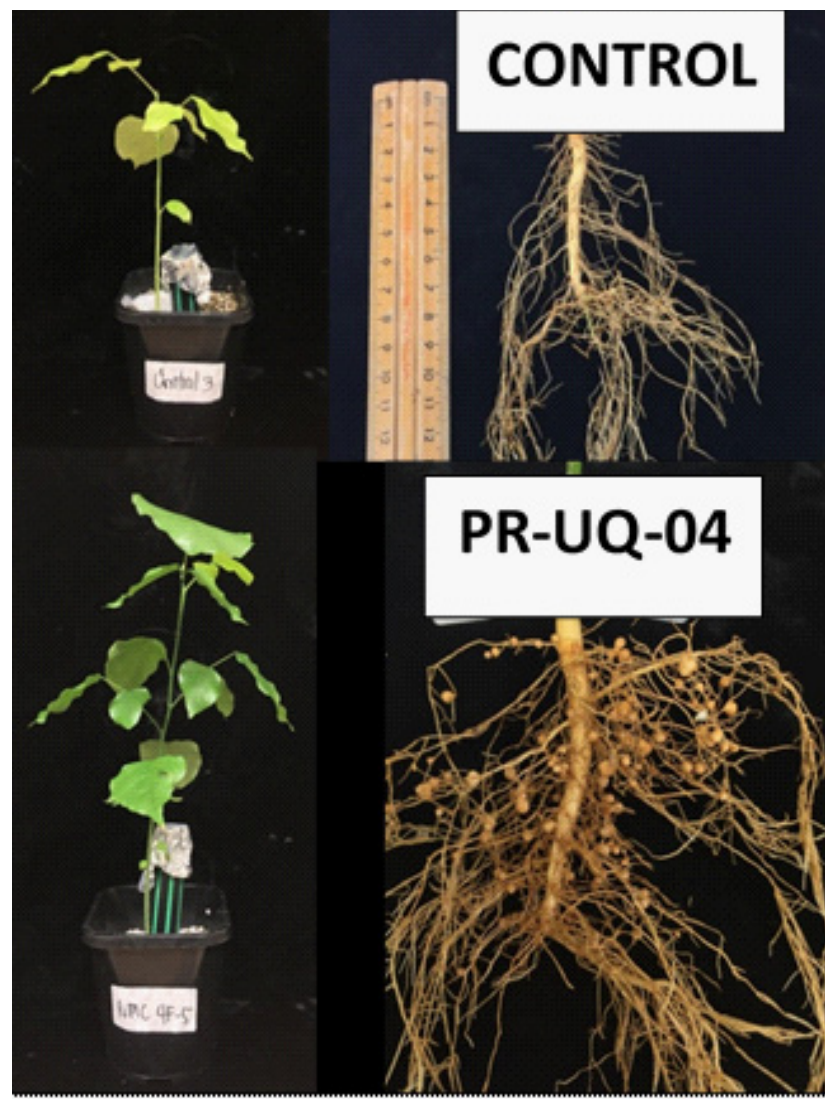

Figure 2. Nodulation of Pongamia pinnata plants. Uninoculated plants (A) were observed to grow poorly having yellowish leaves and stunted growth without nodules (B). Inoculated plants $(C)$ using the isolates from baiting techniques grew better with nodulated roots (D). 
rest were slightly acidic. The mineral levels in Soil 1 were mostly higher than the rest of the soil samples, while Soil 4 and 6 had average levels.

\section{Nodulation and Symbiotic Effectiveness}

Uninoculated plants (control) grew poorly compared with inoculated plants which had higher shoot and root dry weights (see supplemental Table S4). No nodules were found on the uninoculated plants which confirmed their 'no contamination' status. Inoculated plants showed the following: (i) PR-UQ-01 had the highest plant dry weight with 2nd largest nodule number; (ii) PRUQ-03 had highest shoot length, 2nd highest shoot dry weight among the nodule isolates and 2nd highest $\mathrm{N}$ content; (iii) PRUQ-04 had the largest nodule number among the soil isolates (Figure 2) and (iv) PR-UQ-05 had the highest nodule number among the nodule isolates. These four strains were therefore selected for further studies.

\section{Time Course of Nodulation}

All control plants had no nodules from week 4 to 8 as shown in supplemental Table S5. Total plant dry weight increased from $1.23 \mathrm{~g}$ at week 4 up to $2.11 \mathrm{~g}$ in week 8 . The total $\mathrm{N}$ level in shoots and roots increased from $5.12 \% \mathrm{Wt}$ at week 4 to $6.22 \%$ Wt at week 7 but decreased to $5.89 \% \mathrm{Wt}$ on week 8 . PRUQ-03 plants nodulated at week 4 with 38 nodules per plant and continue to produce nodules until week 8 with 80 nodules per plant. The total plant dry weight increased from week 4 at $1.859 \mathrm{~g}$ to week 6 at $2.406 \mathrm{~g}$ but almost without any changes at weeks 7 and 8 . Leghemoglobin concentration at week 4 was $0.132 \mathrm{mg} / \mathrm{ml}$ and increased to $0.640 \mathrm{mg} / \mathrm{ml}$ in week 8 (see Figure 3). The area of zone of infection of the biggest active nodule was $1.58 \mathrm{~mm} 2$ at week 4 and continued to increase its area up to $3.89 \mathrm{~mm} 2$ at week 8 . The total $\mathrm{N}$ level in shoots and roots was $6.56 \% \mathrm{Wt}$ at week 4 and no significant changes until week 8 . On the other hand, PR-UQ-05 plants produced 56 nodules per plant at week 4 which continued to increase until week 8 producing 78 nodules per plant. The total plant dry weight also doubled from $1.139 \mathrm{~g}$ in week 4 up to $2.283 \mathrm{~g}$ at week 8 . Leghemoglobin concentration increased from week 4 at 0.235 $\mathrm{mg} / \mathrm{ml}$ to week 8 at $0.663 \mathrm{mg} / \mathrm{ml}$. The area of zone of infection of its biggest nodule started at $1.86 \mathrm{~mm}^{2}$ at week 4 and increased to $3.08 \mathrm{~mm}^{2}$ at week 8 . The total $\mathrm{N}$ level in shoots and roots was $4.30 \% \mathrm{Wt}$ at week 4 and continued to increase at week 8 measuring $5.12 \% \mathrm{Wt}$.

The inoculation of PR-UQ-05 showed significant increase in nodule number, total plant dry weight, leghemoglobin concentration, area of zone of infection and total $N$ level in shoots and roots from week 4 to week 8 while inoculation with PR-UQ-03 increased nodule number, leghemoglobin concentration and area of zone of infection from week to week 8 and no significant increase for total plant dry weight and total $\mathrm{N}$ level in shoots and roots over the weeks.

\section{Assessment of Nitrogenase Activity}

All nodulated pongamia and soybean (as control) plants inoculated with the best isolates were observed to have nitrogenase activities in their nodules as implicated in the increased acetylene-dependent ethylene production from 0 to 60 minutes sampling time incubated at room temperature as shown in Table 1. In contrast, the non-nodulated, uninoculated controls had zero to almost negligible values. Pongamia plants were observed to have higher nitrogen fixing (i.e., acetylene reduction) activity compared with soybeans when inoculated with PR-UQ-05, but show no significant difference when inoculated with PR-UQ-03.

The $\mathrm{N}$ difference method further confirmed that the new in-

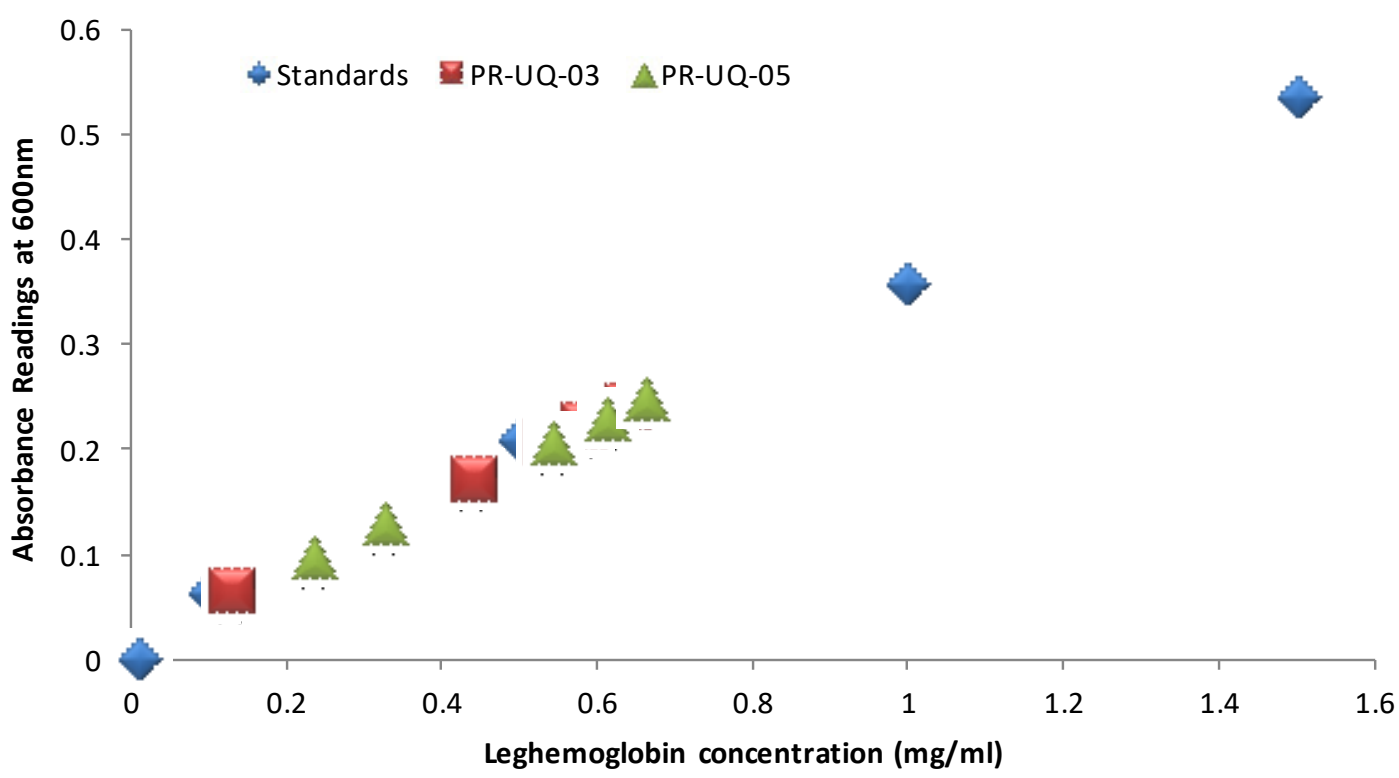

Figure 3. Leghemoglobin content $(\mathrm{mg} / \mathrm{ml})$ versus the absorbance readings at $600 \mathrm{~nm}$ of the standard haemoglobin, PR-UQ-03 nodules and PR-UQ-05 nodules from week 4 to week 8. 
Table 1. Volume of ethylene $(\mathrm{ml})$ produced by pongamia and soybeans inoculated with PR-UQ-03 vs PR-UQ-05 with uninoculated control after 60-minute incubation at room temperature. Values shown were the average of three replicates used per treatment.

\begin{tabular}{cccc}
\hline Treatments & $\begin{array}{c}\text { Volume of ethylene } \\
(\mathrm{ml}) / \text { plant }\end{array}$ & $\begin{array}{c}\text { Number of } \\
\text { nodules/plant }\end{array}$ & $\begin{array}{c}\text { Nodule Fresh } \\
\text { Weight (g)/plant }\end{array}$ \\
\hline PR-UQ-03 - Soybeans & $0.21 \pm 0.01 \mathrm{~ns}$ & $14 \pm 2 \mathrm{c}$ & $0.01 \pm 0 \mathrm{c}$ \\
PR-UQ-03 - Pongamia & $0.30 \pm 0 \mathrm{~ns}$ & $65 \pm 2.03 \mathrm{~b}$ & $0.50 \pm 0.01 \mathrm{~b}$ \\
PR-UQ-05 - Soybeans & $0.06 \pm 0.03 \mathrm{~ns}$ & $17 \pm 7.36 \mathrm{c}$ & $0.02 \pm 0.01 \mathrm{c}$ \\
PR-UQ-05 - Pongamia & $2.76 \pm 1.18 \mathrm{~ns}$ & $86 \pm 3.06 \mathrm{a}$ & $0.868 \pm 0.03 \mathrm{a}$ \\
\hline
\end{tabular}

* Values followed by the same letter are not significantly different at $5 \%$ significance level. ns $=$ not significantly different(Standard Error).

Table 2. The nitrogen difference method to estimate fixed nitrogen of Pongamia pinnata inoculated with the isolates compared with CB564 and uninoculated control for 12-week growth period under glasshouse conditions.

\begin{tabular}{lcccccc}
\hline Treatments & $\begin{array}{c}\text { Shoot Nitrogen } \\
\text { Content (wt \%) }\end{array}$ & $\begin{array}{c}\text { Root Nitrogen } \\
\text { Content (wt } \\
\%)\end{array}$ & $\begin{array}{c}\text { Total Nitrogen } \\
\text { Content }(w t \\
\%)\end{array}$ & $\begin{array}{c}\text { N Fixed* } \\
\text { (wt\%) }\end{array}$ & $\begin{array}{c}\text { Total Plant } \\
\text { Dry Weight } \\
\text { (Grams) }\end{array}$ & $\begin{array}{c}\text { N } \\
\text { Fixed/g } \\
\text { Dry Wt }\end{array}$ \\
\hline $\begin{array}{l}\text { Uninoculated } \\
\text { Control }\end{array}$ & $1.24 \pm 0.05 \mathrm{c}$ & $1.18 \pm 0.06 \mathrm{c}$ & $2.42 \pm 0.10 \mathrm{~b}$ & $0 \mathrm{~b}$ & 1.991 & 0 \\
CB564 & $2.87 \pm 0.30 \mathrm{ab}$ & $2.2 \pm 0.26 \mathrm{ab}$ & $5.07 \pm 0.53 \mathrm{a}$ & $2.65 \mathrm{a}$ & 2.157 & 1.229 \\
PR-UQ-03 & $3.55 \pm 0.16 \mathrm{a}$ & $2.59 \pm 0.18 \mathrm{a}$ & $6.15 \pm 0.32 \mathrm{a}$ & $3.73 \mathrm{a}$ & 2.452 & 1.521 \\
PR-UQ-05 & $3.46 \pm 0.47 \mathrm{a}$ & $2.56 \pm 0.42 \mathrm{a}$ & $6.02 \pm 0.88 \mathrm{a}$ & $3.6 \mathrm{a}$ & 2.777 & 1.296 \\
\hline
\end{tabular}

* Values followed by the same letter are not significantly different at $5 \%$ significance level. Shown are the mean values and SE. Legend: yellow highlights - high values; blue highlights - low values. ${ }^{*} \mathrm{~N}$ fixed (wt\%/g DW) $=\mathrm{N}$ yield by inoculated plant (wt\%) $-\mathrm{N}$ yield by uninoculated plants (wt\%).

oculant isolates PR-UQ-03 and PR-UQ-05 aid in the nitrogen fixation of pongamia as seen in the increase of $\mathrm{N}$ level content in the shoots and roots of pongamia seedlings in a 12-week growth period (See Table 2). Inoculated plants had higher $\mathrm{N}$ level content in shoots and root compared with uninoculated control and CB564. Consistently, pongamia plants inoculated with PR-UQ-05 had the highest nodule number, nodule fresh weight and nitrogen fixation activity.

\section{Characterisation of the 'Best' Rhizobial Inoculant}

The selected rhizobia PR-UQ-01 and PR-UQ-03 were able to utilise mannitol as the only carbon source. PR-UQ-03 grew within 5 days of incubation, thus considered a "fast grower", while PR-UQ-01 appeared within 6-10 days of incubation making it a "slow grower". Suppplemental Table S2 summarises the characteristics of all the 21 isolates on YEMA+CR and with six different types of antibiotics (10 mg/L in media).

The rhizobia PR-UQ-03 and PR-UQ-05 were selected as "best" among the 21 isolates due to their symbiotic performance and being the fast-growers. Both strains were grown into Yeast extract mannitol agar with Congo Red with varying incubation temperatures $\left(22^{\circ} \mathrm{C}, 37^{\circ} \mathrm{C}\right.$, and $\left.45^{\circ} \mathrm{C}\right)$; different $\mathrm{pH}(4,7$ and 9) and on different $\mathrm{NaCl}$ concentration $(0.1 \%, 0.5 \%$ and $1 \%)$. Both PR-UQ-03 and PR-UQ-05 can grow on $\mathrm{pH} 7.0$ media only. Also both strains were able to survive at $22^{\circ} \mathrm{C}$ incubation, but did not grow at $37^{\circ} \mathrm{C}$ and $45^{\circ} \mathrm{C}$. Both PR-UQ-03 and PR-UQ-05 were able to grow on $0.1 \%$ and $0.5 \% \mathrm{NaCl}$ supplementation of the medium. Both rhizobia isolates did not grow on $1 \% \mathrm{NaCl}$ supplementation.

The size of the colonies also observed to vary among strains grown on the different media. At $\mathrm{pH} 7.0$ and $0.1 \% \mathrm{NaCl}$ supplemented media incubated at $28^{\circ} \mathrm{C}$, colonies of PR-UQ-05 were bigger in size (1-2 mm diameter) compared to colonies on $0.5 \%$ $\mathrm{NaCl}$ media (at $28^{\circ} \mathrm{C}$ ) and on normal media at $22^{\circ} \mathrm{C}$ incubation. The number of colonies of PR-UQ-05 at $22^{\circ} \mathrm{C}$ was also decreased by $25 \%$. The cold incubation affects the growth of PR-UQ-05 but did not totally inhibit the rhizobia growth. PRUQ-03 colonies were lesser in number but definitely bigger in size ( $3 \mathrm{~mm}$ diameter) except those that grew on $0.5 \% \mathrm{NaCl}$ (1-2 $\mathrm{mm}$ diam) compared with PR-UQ-05. No growth was observed in all control plates (inoculated with sterile distilled water only). Supplemental Table S6 shows the characteristics of the selected rhizobia PR-UQ-03 and PR-UQ-05.

\section{Identification and Molecular Characterisation of the Best Rhizobia}

DNA was extracted successfully from the four selected rhizobia strains: PR-UQ-01, PR-UQ-03, PR-UR-04 and PR-UQ-05 and was subjected to PCR using primers $27 F$ and $1492 R$. Results showed that $16 \mathrm{~S}$ rDNA of the four isolates was amplified which was further used for DNA sequencing. See supplemental Figure S2.

The predicted molecular band (1,250 bp) from the PCR gel was extracted and purified. Another gel electrophoresis using the purified PCR products was done to confirm one single 
Rhizobium pongamiae strain VKLR-01

Rhizobium mongolense strain USDA 1844

Rhizobium yanglingense strain $\mathrm{SH} 22623$

Rhizobium loessence strain CCBAU 7190B

Rhizobium sullae strain IS 123

Rhizobium alamii strain GBV016

Rhizobium mesosinicum strain CCBAU 25010

- Bradyrhizobium denitrificans strain LMG 8443

Bradyrhizobium arachidis CCBAU 051107

Bradyrhizobium sp. DOA10

Bradyrhizobium betae strain NBRC 103048

Bradyrhizobium iriomotense strain NBRC 102520

Bradyrhizobium huanghuaihaiense strain CCBAU 23303

Bradyrhizobium diazoefficiens strain USDA 110

Bradyrhizobium oligotrophicum strain S58

Bradyrhizobium yuanmingse strain NBRC 100594

Bradyrhizobium liaoningense strain 2281

Bradyrhizobium jicamae strain PAC68

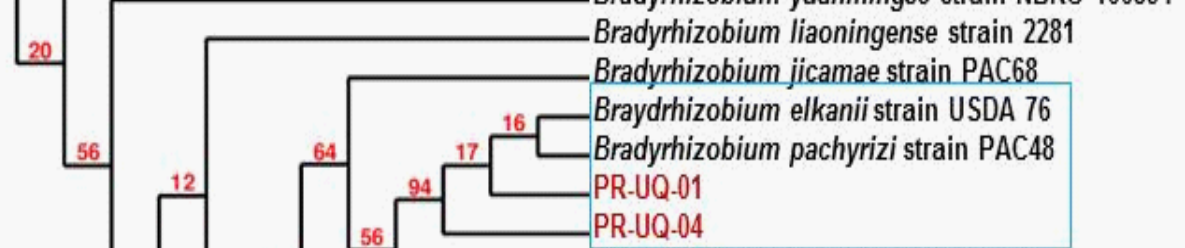

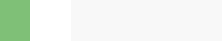
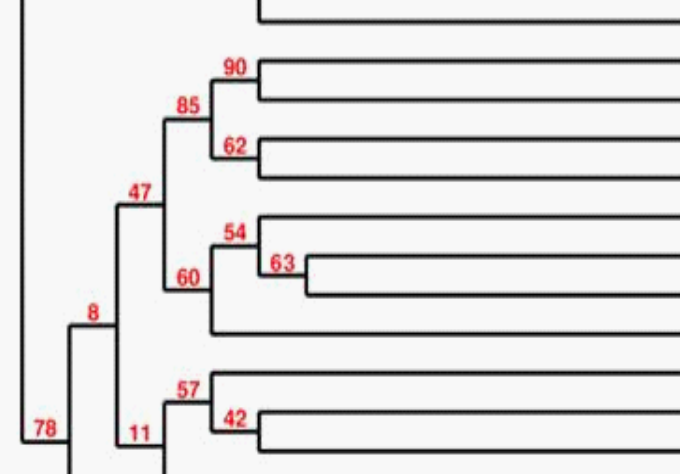

Bradyrhizobium lablabi strain CCBAU

Bradyrhizobium retamae strain Ro19

Bradyrhizobium valentinum strain LmjM3

Bradyrhizobium canariense strain NBRC

Bradyrhizobium japonicum strain 311b6

Bradyrhizobium daqingense strain CCBAU 15774

Rhizobium indigoferae strain NBRC 100398

Rhizobium leguminosarum bv. vicae 3841 strain 3841

Rhizobium lusitanum strain P1.7

Rhizobium miluonense strain CCBAU 33202

Rhizobium fabae strain CCBAU 33202

Rhizobium etli strain CFN 42

Rhizobium pisi strain DSM 30132

Rhizobium phaseoli strain NBRC 14785

Rhizobium endophyticum strain CCGE 2052

Rhizobium tibeticum strain CCBAU 85039

Rhizobium grahamii strain CCGE 502

Rhizobium tubonense strain CCBAU 85046

Rhizobium mesoamericanum strain CCGE 501

PR.UQ-03

PR.UQ-05

Escherichia coli strain AE1-2

Figure 4. Phylogenetic relationship among the four rhizobial isolates nodulating pongamia (Dereeper et al., 2008).

band amplified. All four rhizobia strains produced only a single molecular band; thus, the PCR products were purified. Restriction enzyme digestion using the three enzymes-Acll, Dpnlll and Haelll, was done to confirm that the four rhizobia strains belong to different genera. Results showed that the pattern of band fragments differed among the four strains implicating that they belong to different genera. Purified PCR products were then sequenced at AGRF (Brisbane, Australia) and the resulting sequences were subjected to BLAST and phylogenetic analysis.

BLAST results: (e values $=0$ ) revealed that PR-UQ-01 is Bradyrhizobium elkanii, PR-UQ-03 is Rhizobium mesoamericanum, PRUQ-04 is Bradyrhizobium elkanii and B. pachyrizi and PR-UQ-05 is Rhizobium mesoamericanum (all at $99 \%$ certainty). Comparison of sequences using BLAST alignment between PR-UQ-01 and 04 as well as PR-UQ-03 and 05 revealed that these two sets of strains were highly similar (>99\%), although the restriction nuclease digestion pattern and symbiotic tests results differ among them.

Figure 4 shows the phylogenetic analysis of the four selected isolates compared with other rhizobia strains which revealed that both PR-UQ-01 and PR-UQ-04 were closely related to Bradyrhizobium elkanii and $B$. pachyrizi with bootstrap value of 94 while PR-UQ-03 and PR-UQ-05 were both closely related to Rhizobium mesoamericanum with a boostrap value of 89 . 


\section{Discussion}

The basis of all the experimental setups in this study was derived from the cotyledon experiment which was performed to determine the role of cotyledon in nodulation and growth of pongamia seedlings and to avoid the carry-over of nutrient from the cotyledon to the plants which might affect the results of the succeeding experiments. Cotyledon experiment had shown that all of the uninoculated treatments did not produce nodules which implied good glasshouse maintenance. The addition of nutrient solution lessens the variation between replicate plants in each treatment. Both inoculated treatments were able to produce several nodules but higher number was observed in the treatments with nutrient solution. Hence, the addition of nutrient solution at the described rate (weak in normal horticulture) improved the nodulation of pongamia. The appearance of visible difference in growth conditions among the inoculated, uninoculated, with or without nutrient solution and with nitrogen treatment plants had been obvious earlier in plants with both cotyledons halved. Growth variations were noted in just 3-4 weeks after inoculation while variations for other plants (either both cotyledons intact, one removed or both cotyledons removed), were observed at later stages of around 7-8 weeks after inoculation or at harvesting. This implied that the cotyledons affect the nodulation and growth of pongamia. By cutting both cotyledons into halves, the nutrient carry-over will be controlled and thus the variation of result can be now attributed to the different treatments and not to nutrients in cotyledon. Therefore, the cotyledon factor will now be eliminated in future studies by simply cutting the cotyledons into halves. Moreover, the pongamia cotyledon can also provide enough nutrients for the plants to grow even up to 16 weeks with or without nutrient solution added.

This study was able to successfully isolate a total of 21 potential rhizobia from the different soil samples in a mining site in Kingaroy, Queensland where pongamia had been grown to rehabilitate the area while the pongamia nodules used in the isolation were collected from Botanical Gardens in Mt. Coot-tha, Queensland where pongamia were introduced several years ago. Out of the six soil samples located in different areas in the mining sites, only two produced nodules in the baited pongamia seedlings which can be attributed to the presence of average level of nutrients (not too high or low), pH and loamy soil characteristics which can support rhizobia growth. The baiting experiment using these soil samples from mining sites further revealed that rhizobia that can nodulate pongamia are present in the soil with poor nutrient conditions and where pongamia are not previously grown.

To determine the best strains, the 21 isolates from the baiting experiment and isolation from pongamia nodule were screened for strain symbiotic effectiveness by inoculating into pongamia under uniform growth conditions. Four strains PR-UQ-01, PRUQ-03, PR-UQ-04 and PR-UQ-05 showed promising results in the screening test but the fast growers PR-UQ-03 and PR-UQ-05 were selected and were used as inoculants for the other experiments beause PR-UQ-03 had highest shoot length, 2nd highest shoot dry weight among the nodule isolates and 2nd highest $\mathrm{N}$ content while PR-UQ-05 had the highest nodule number among the nodule isolates.

In the time course of nodulation experiment, the inoculation of PR-UQ-05 showed significant increase in nodule number, total plant dry weight, leghemoglobin concentration, area of zone of infection and total $\mathrm{N}$ level in shoots and roots from week 4 to week 8 while inoculation with PR-UQ-03 increased nodule number, leghemoglobin concentration and area of zone of infection from week 4 to week 8 and no significant increase for total plant dry weight and total $\mathrm{N}$ level in shoots and roots over the weeks. This implied that both strains improved nodulation in pongamia. This results is further supported by the acetylene reduction assay and $\mathrm{N}$ difference method which revealed that nodulated pongamia inoculated with PR-UQ-03 and PR-UQ-05 were observed to have nitrogenase activities in their nodules. The nitrogen fixation present in the nodules of the inoculated plants contributed to the better growth conditions and nodulation of these plants. Pongamia plants were observed to have higher nitrogen fixing (i.e., acetylene reduction) activity compared with soybeans when inoculated with PR-UQ-05, but show no significant difference when inoculated with PR-UQ-03. This means that PR-UQ-03 and PR-UQ-05 have low symbiotic effectiveness with soybeans as soybeans are known to be strain specific legumes while pongamia on the other hand, is known to be promiscuous legume and can be nodulated with any species of rhizobia. The $\mathrm{N}$ difference method further confirmed that the new inoculant isolates PR-UQ-03 and PR-UQ-05 aid in the nitrogen fixation of pongamia as seen in the increase of $\mathrm{N}$ level content in the shoots and roots of pongamia seedlings in a 12 -week growth period.

PR-UQ-03 and PR-UQ-05 were both isolated from pongamia nodules. PR-UQ-03 had 2-3 mm diam colonies which were white/creamy, high convex and slimy while PR-UQ-05 had 3-4 $\mathrm{mm}$ diam colonies with white but prolong incubation observed to produced red center, high convex and very slimy. Both utilised mannitol as the only carbon source, "fast growers", had optimum growth at $\mathrm{pH} 7.0$, temperature of $28^{\circ} \mathrm{C}$ although it can survive at $22^{\circ} \mathrm{C}$, and in yeast extract mannitol agar with $0.1 \%$ to $0.5 \%$ $\mathrm{NaCl}$. Both strains were resistant to AMP, SPEC and TET. 16S rDNA amplification of both strains yielded 1250 bp using primers $27 \mathrm{~F}$ and $1492 \mathrm{R}$. BLAST results: (e values $=0$ ) revealed that both PR-UQ-03 and PR-UQ-05 are related to Rhizobium mesoamericanum (all at $99 \%$ certainty). Comparison of sequences using BLAST PR-UQ-03 and 05 revealed that these strains were highly similar (>99\%), although the restriction nuclease digestion pattern and symbiotic tests results differ between them. Phylogenetic analysis revealed that both PR-UQ-03 and PR-UQ-05 were both closely related to Rhizobium mesoamericanum with a boostrap value of 89 .

\section{Conclusions and Future Work}

Pongamia plants can fix nitrogen from their efficient symbiosis with either fast or slow-growing rhizobia with nodules starting to form within 2-3 weeks after inoculation and continuing throughout the tested 10-12 weeks growth period. Cutting both cotyledons in halves had little effect on shoot dry weight, nodule number and weight per plant at 8 weeks, but were reduced when both cotyledons were removed and plants were visibly yellow. 
By cutting both cotyledons into halves, the nutrient carry-over will be controlled and thus the variation of result can be now attributed to the different treatments and not to nutrients in cotyledon. Therefore, the cotyledon factor will now be eliminated in future studies by simply cutting the cotyledons into halves. Surprisingly when no nutrients were supplied and with both cotyledons intact, plants grew as well as those with nutrients. Cotyledons supply the seedling with nutrients for a considerable period of early growth (8 to 16 weeks after germination), while symbiotic nitrogen fixation supports pongamia on its later growth and eventual reproduction (flowering and seed formation).

The fast growers, Rhizobium-related strains PR-UQ-03 and PR-UQ-05, isolated from pongamia nodules are likely the best rhizobia strains among the 21 isolates with confirmed nodulation and symbiotic effectiveness in pongamia and with an established active nitrogenase activity.

Further study is still recommended to test the survival of these rhizobia strains in the field to be used in the improvement of plant performance in soil where native rhizobia nodulating pongamia are sparse or absent.

\section{Abbreviations}

PR-UQ: Pongamia Rhizobia-University of Queensland

CB: CSIRO Brisbane

USDA: United States Department of Agriculture

COT: Cotyledon

B\&D: Broughton and Dilworth

YEMA: Yeast extract mannitol agar

YMB: Yeast extract mannitol broth

CR: Congo red

ARA: Acetylene reduction assay

\section{Competing Interests}

The author declares that they have no competing interests.

\section{Authors Contributions}

PNC conducted experiments, evaluated results and wrote the manuscript. Al, PS, PD and PMG contributed to the conception, interpretation and supervision of the research. PMG and PNC revised and edited the manuscript. Al performed the statistical analysis.

\section{Acknowledgements}

The authors would like to thank the ARC Linkage Project LP1 20200562 of the Centre for Integrative Legume Research (CILR) at the University of Queensland for the funding of this research and AusAID for the scholarship given to PNC to pursue her PhD at The University of Queensland, Australia. Members of the CILR are thanked for help and advice.

\section{References}

Arpiwi NL, Yan G, Barbour EL, Plummer JA, and E Watkin (2012) Pheno- typic and genotypic characterisation of root nodule bacteria nodulating Millettia pinnata (L.) Panigrahi, a biodiesel tree. Plant and Soil 367: 363-377.

Bergersen FJ, Turner GL, Bogusz D and CA Appleby (1988) Fixation of N2 by bacteroids from stem nodules of Sesbania rostrata. Journal of General Microbiology 134: 1807-1810.

Biswas B, Kazakoff SH, Jiang QY, and S Samuel (2013) Genetic and genomic analysis of the tree legume Pongamia pinnata as a feedstock for biofuels. The Plant Genome 6:1-15.

Biswas B and PM Gresshoff (2014) The role of symbiotic nitrogen fixation in sustainable production of biofuels. International Journal of Molecular Sciences 15: 7380-7397.

Chandrasekaran D, Kadirvel R, and K Viswanathan (1989) Nutritive value of pungam (Pongamia glabra Vent) cake for sheep. Animal Feed Science and Technology 22: $321-325$.

Dereeper A, Guignon V, Blanc G, Audic S, Buffet S, Chevenet F, Dufayard JF, Guindon S, Lefort V, Lescot $M$, Claverie JM and O Gasquel (2008) Phylogeny.fr: robust phylogenetic analysis for the non-specialist. Nucleic Acids Research 36: W465-W469.

Dorsch $M$, and E Stackebrandt (1992) Some modifications in the procedure of direct sequencing of PCR amplified 16S rDNA. Journal of Microbiological Methods 16: 271-279.

Dwivedi G, Jain S, and MP Sharma (2011) Pongamia as a source of biodiesel in India. Smart Grid and Renewable Energy 2: 184-189.

Gault RR, and EA Schwinghamer (1993) Direct isolation of Bradyrhizobium japonicum from soil. Soil Biology and Biochemistry 25: 1161 1166.

Goodfellow M, and E Stackebrandt (1991) Nucleic acid techniques in bacterial systematics. Wiley, New York, pp. 205-248.

Gresshoff PM, Hayashi S, Biswas B., Mirzaei S, Indrasumunar A, Reid D, Samuel S, Tollenaere A, van Hameren B, Hastwell A, Scott P and BJ Ferguson (2015) The value of biodiversity in legume symbiotic nitrogen fixation and nodulation for biofuel and food production. Journal of Plant Physiology 172: 128-136.

Kazakoff SH, Gresshoff PM, and PT Scott (2011) Pongamia pinnata, a sustainable feedstock for biodiesel production. Issues in Environmental Science and Technology: 233-258.

Kazakoff SH, Imelfort M, Edwards D, Koehorst J, Biswas B, Batley J, Scott PT, and PM Gresshoff (2012) Capturing the biofuel wellhead and powerhouse: The chloroplast and mitochondrial genomes of the leguminous feedstock tree Pongamia pinnata. PLoS ONE 7: e51687.

Kesari V, Ramesh AM, and L Rangan (2013) Rhizobium pongamiae sp. nov. from Root Nodules of Pongamia pinnata. BioMed Research International 2013:165198.

Kesari V, and L Rangan (2010) Development of Pongamia pinnata as an alternative biofuel crop - current status and scope of plantations in India. Journal of Crop Science and Biotechnology 13: 127-137.

Klein-Marcuschamer D, Turner C, Allen M, Gray P, Dietzgen RG, Gray P, Gresshoff PM, Hankamer B, Heimann K, Scott PT, Speight R, Stephens E and LK Nielsen (2013) Technoeconomic analysis of renewable aviation fuel from microalgae, Pongamia pinnata, and sugarcane. Biofuels, Bioproducts and Biorefining 7: 416-428.

Konwar BKB (1987a) Deoiled karanja cake (Pongamia glabra Vent.) a new feed ingredient in cattle ration. Indian Veterinary Journal 64: 500-504.

Konwar BKB and L Mandal (1984) Nutritive value of deoiled karanja cake (Pongamia glabra Vent.) in adult cattle. Indian Journal of Animal Sciences 54: 489-490.

Konwar BKB and L Mandal (1987b) Effect of feeding deoiled Karanja (Pongamia glabra Vent.) cake on growing calves. Indian Veterinary Journal 64: 399-402.

Konwar BKB and L Mandal (1987c) Effect of feeding deoiled karanja 
(Pongamia glabra Vent.) cake on the quantity and quality of milk in cross-bred cows. Indian Veterinary Journal 64: 62-65.

Moreira FMS, Siqueira JO and L Brussaard (2006) Soil biodiversity in Amazonian and other Brazilian ecosystems. CABI Pub, Cambridge MA, Wallingford, UK, pp. 237-262.

Murphy HT, O'Connell, DA, Seaton G, Raison RJ, Rodriguez LC, Braid AL, Kriticos DJ, Jovanovic T, Abadi A, Betar M, Brodie H, Lamont $M$, McKay M, Meirhead G, Plummer J, Arpiwi NL, Ruddle B, Saxena S, Scott PT, Stucley C, Thistlethwaite B, Wheaton B, Wylie P and PM Gresshoff (2012) A common view of the opportunities, challenges, and research actions for pongamia in Australia. BioEnergy Research 5: 778-800.

Naik M, Meher LC, Naik SN, and LM Das (2008) Production of biodiesel from high free fatty acid Karanja (Pongamia pinnata) oil. Biomass and Bioenergy 32: 354-357.

Natanam R, Kadirvel R and R Balagopal (1989a) The effect of kernels of karanja (Pongamia glabra Vent) on growth and feed efficiency in broiler chicks to 4 weeks of age. Animal Feed Science and Technology 25: 201-206.

Natanam R, Kadirvel R and R Ravi (1989b) The toxic effects of karanja (Pongamia glabra Vent) oil and cake on growth and feed efficiency in broiler chicks. Animal Feed Science and Technology 27: 95-100.

Natanam R, Kadirvel R and K Viswanathan (1989c) The effect of karanja (Pongamia glabra Vent) cake on the performance of White
Leghorn pullets. Animal Feed Science and Technology 27: 89-93.

Natanam R, Kardivel R and D Chandrasekaran (1989) Chemical composition of karania (Pongamia glabra Vent [P. pinnata]) kernel and cake as animal feed. Indian Journal of Animal Nutrition 6: 270-273.

Pueppke SG and WJ Broughton (1999) Rhizobium sp. Strain NGR234 and R. fredii USDA257 share exceptionally broad, nested host ranges. Molecular Plant-Microbe Interactions 12: 293-318.

Rasul A, Amalraj ELD, Praveen Kumar G, Grover M and B Venkateswarlu (2012) Characterization of rhizobial isolates nodulating Millettia pinnata in India. FEMS Microbiology Letters 336: 148-158.

Ravi U, Singh P, Garg AK and DK Agrawal (2000) Performance of lambs fed expeller pressed and solvent extracted karani (Pongamia pinnata) oil cake. Animal Feed Science and Technology 88: 121128.

Samuel S, Scott PT and PM Gresshoff (2013) Nodulation in the legume biofuel feedstock tree Pongamia pinnata. Agricultural Research 2: 207-214.

Scott PT, Pregelj L, Chen N, Hadler JS, Diordjevic MA and PM Gresshoff (2008) Pongamia pinnata: An untapped resource for the biofuels industry of the future. BioEnergy Research 1: 2-11.

Singh P, Sastry VRB, Garg AK, Sharma AK, Singh GR and DK Agrawal (2006) Effect of long term feeding of expeller pressed and solvent extracted karani (Pongamia pinnata) seed cake on the performance of lambs. Animal Feed Science and Technology 126: 157-167. 


\section{Nemenzo-Calica et al., 2016 - Supplementary Data}

Table S1. Effect of cotyledon in nodulation of Pongamia pinnata seedlings under glasshouse conditions for 16 weeks growth period.

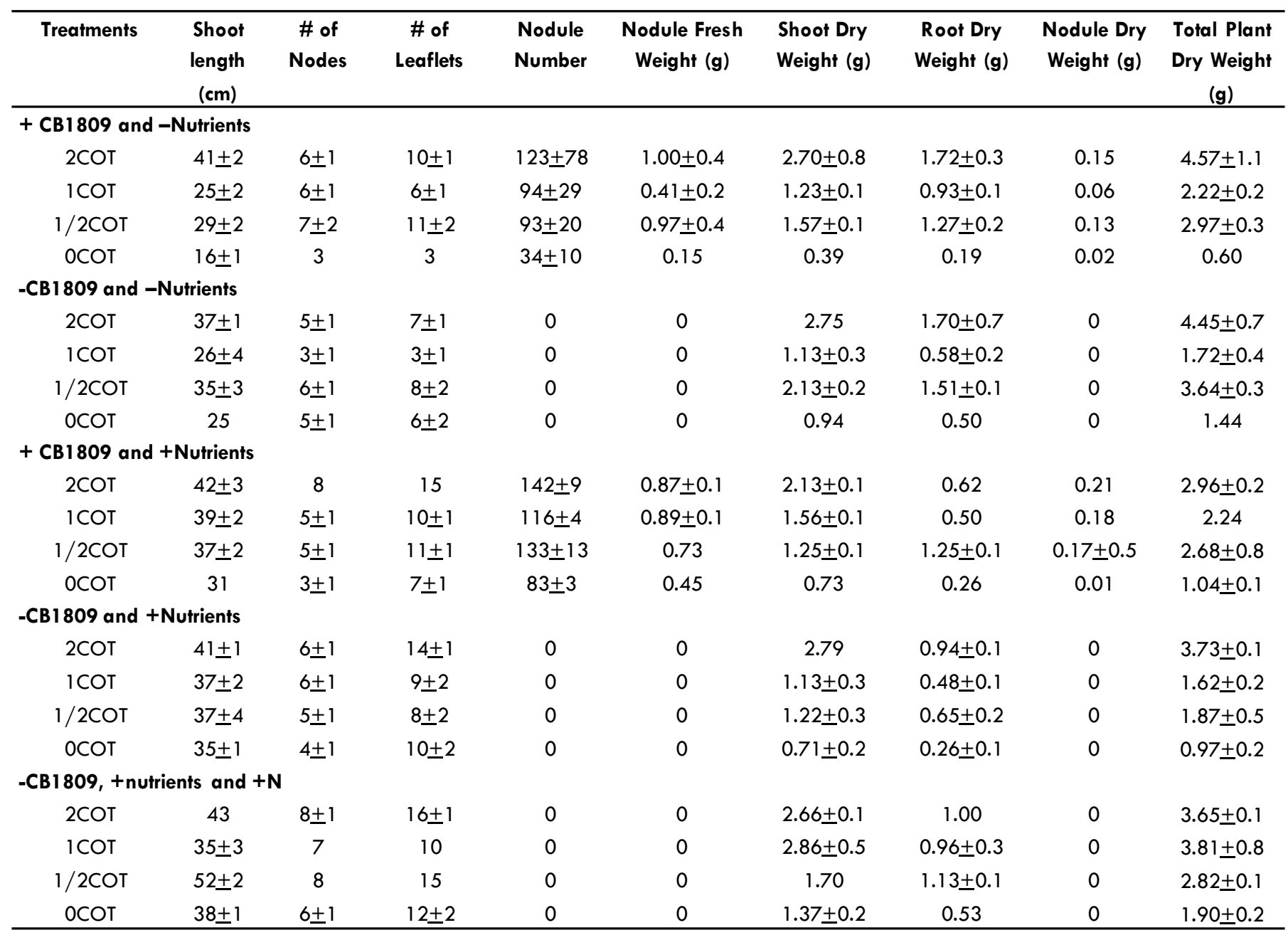

Shown are the mean values and standard errors for the two replicates used in each treatment. Legend: OCOT $=$ Both $\infty$ otyledons were removed; 1 COT $=$ One $\infty$ tyledon removed; $2 \mathrm{COT}=$ Both cotyle dons intact; $1 / 2 \mathrm{COT}=$ Both cotyle dons cut into halves. 
Table S2. Putative rhizobia isolated from different soil samples and pongamia nodules.

\begin{tabular}{|c|c|c|}
\hline Code & Origin & Morphological/Physiological Characteristics \\
\hline PR-UQ-01 & Meandu Mine Soil 6 & $\begin{array}{l}\text { Slow-grower; Resistant to AMP, SPEC, TET \& KAN; 1-1.5 mm } \\
\text { diam; whitish-pinkish; flat; circular; slimy }\end{array}$ \\
\hline PR-UQ-02 & Pongamia Nodule (Mt. Coot-tha) & $\begin{array}{l}\text { Fast-grower; Resistant to AMP and TET; } 1 \mathrm{~mm} \text { diam; white; } \\
\text { circular; low convex; slimy }\end{array}$ \\
\hline PR-UQ-03 & Pongamia Nodule (Mt. Coot-tha) & $\begin{array}{l}\text { Fast-grower; Resistant to AMP, SPEC \& TET; } 2-4 \mathrm{~mm} \text { diam; white; } \\
\text { high convex; very slimy }\end{array}$ \\
\hline PR-UQ-04 & Meandu Mine Soil 4 & $\begin{array}{l}\text { Slow-grower; Resistant to AMP, SPEC \& TET; 1-1.5 mm diam; } \\
\text { whitish-pinkish; flat; circular; slimy }\end{array}$ \\
\hline PR-UQ-05 & Pongamia Nodule (Mt. Coot-tha) & $\begin{array}{l}\text { Fast-grower; Resistant to AMP, SPEC \& TET; } 2-4 \mathrm{~mm} \text { diam; white; } \\
\text { high convex; very slimy }\end{array}$ \\
\hline PR-UQ-06 & Meandu Mine Soil 4 & $\begin{array}{l}\text { Fast-grower; Resistant to AMP, SPEC \& TET; } 1 \text { mm diam; white- } \\
\text { pinkish; low convex; circular; slimy }\end{array}$ \\
\hline PR-UQ-07 & Meandu Mine Soil 6 & $\begin{array}{l}\text { Fast-grower; Resistant to AMP, SPEC \& TET; } 2.5-3 \mathrm{~mm} \text { diam; } \\
\text { pinkish-reddish; flat to low convex; irregular shape; very slimy }\end{array}$ \\
\hline PR-UQ-08 & Meandu Mine Soil 6 & $\begin{array}{l}\text { Slow-grower; Resistant to AMP \& TET; } 0.5 \mathrm{~mm} \text { diam; white- } \\
\text { pinkish; flat to low convex; circular; slimy }\end{array}$ \\
\hline PR-UQ-09 & Pongamia Nodule (Mt. Coot-tha) & $\begin{array}{l}\text { Fast-grower; Resistant to RIF and AMP; } 3-4 \mathrm{~mm} \text { diam; white; high } \\
\text { convex; circular; very slimy }\end{array}$ \\
\hline PR-UQ-10 & Pongamia Nodule (Mt. Coot-tha) & $\begin{array}{l}\text { Fast-grower; Susceptible to all tested antibiotics; } 3-4 \mathrm{~mm} \text { diam; } \\
\text { semi-transluscent; flat; circular; slimy }\end{array}$ \\
\hline PR-UQ-11 & Pongamia Nodule (Mt. Coot-tha) & $\begin{array}{l}\text { Fast-grower; Resistant to RIF, AMP, STR, SPEC, TET and KAN; } 2 \\
\text { mm diam; white; flat; circular; slimy }\end{array}$ \\
\hline PR-UQ-12 & Pongamia Nodule (Mt. Coot-tha) & $\begin{array}{l}\text { Fast-grower; Resistant to RIF, AMP, STR, SPEC, TET and KAN; 3-4 } \\
\text { mm diam; reddish; low convex; circular; slimy }\end{array}$ \\
\hline PR-UQ-13 & Pongamia Nodule (Mt. Coot-tha) & $\begin{array}{l}\text { Fast-grower; Resistant to RIF, AMP, STR, SPEC and TET; } 1 \mathrm{~mm} \\
\text { diam; white; flat to low convex; circular; slimy }\end{array}$ \\
\hline PR-UQ-14 & Pongamia Nodule (Mt. Coot-tha) & $\begin{array}{l}\text { Fast-grower; Resistant to RIF and AMP; } 3-4 \mathrm{~mm} \text { diam; white; high } \\
\text { convex; circular; very slimy }\end{array}$ \\
\hline PR-UQ-15 & Pongamia Nodule (Mt. Coot-tha) & $\begin{array}{l}\text { Fast-grower; Resistant to RIF, AMP, STR, SPEC and KAN; } 2 \mathrm{~mm} \\
\text { diam; white; low convex; circular; slimy }\end{array}$ \\
\hline$P R-U Q-16$ & Pongamia Nodule (Mt. Coot-tha) & $\begin{array}{l}\text { Fast-grower; Resistant to RIF, AMP, STR, SPEC, TET and KAN; 3-4 } \\
\text { mm diam; opalescent; flat; circular to irregular; slimy }\end{array}$ \\
\hline PR-UQ-17 & Pongamia Nodule (Mt. Coot-tha) & $\begin{array}{l}\text { Fast-grower; Resistant to RIF, AMP, STR and KAN; 3-4 mm diam; } \\
\text { reddish; irregula; flat; slimy }\end{array}$ \\
\hline PR-UQ-18 & Pongamia Nodule (Mt. Coot-tha) & $\begin{array}{l}\text { Slow-grower; Resistant to RIF, AMP, STR, SPEC and TET; } 1 \mathrm{~mm} \\
\text { diam; white; circular; flat/low convex; slimy }\end{array}$ \\
\hline PR-UQ-19 & Pongamia Nodule (Mt. Coot-tha) & $\begin{array}{l}\text { Slow-grower; Resistant to RIF, AMP, STR, SPEC and TET; } 1 \mathrm{~mm} \\
\text { diam; white; circular; flat/low convex; slimy }\end{array}$ \\
\hline PR-UQ-20 & Pongamia Nodule (Mt. Coot-tha) & $\begin{array}{l}\text { Slow-grower; Resistant to RIF, AMP, STR, SPEC and TET; } 1 \mathrm{~mm} \\
\text { diam; white; circular; flat/low convex; slimy }\end{array}$ \\
\hline PR-UQ-21 & Pongamia Nodule (Mt. Coot-tha) & $\begin{array}{l}\text { Slow-grower; Resistant to RIF, AMP, STR, SPEC and TET; } 1 \mathrm{~mm} \\
\text { diam; white; circular; flat/low convex; slimy }\end{array}$ \\
\hline
\end{tabular}


Table S3. The physical property, pH, N level and mineral content of the soil samples.

\begin{tabular}{|c|c|c|c|c|c|c|}
\hline Parameters & MM Soil 1 & MM Soil 2 & MM Soil 3 & MM Soil 4 & MM Soil 5 & MM Soil 6 \\
\hline Source & $\begin{array}{c}\text { Kingaroy } 2 \text { East } \\
\text { Shale/ } \\
\text { Sandstone }\end{array}$ & $\begin{array}{c}\text { Farmhouse } \\
\text { Control } \\
\text { Site D3 }\end{array}$ & $\begin{array}{c}\text { Southwest } \\
\text { Control Site } \\
\text { D5 }\end{array}$ & $\begin{array}{c}\text { Southwest } \\
\text { Spoil }\end{array}$ & $\begin{array}{l}\text { Southwest } \\
\text { Topsoil }\end{array}$ & $\begin{array}{l}\text { Kingaroy } 2 \\
\text { East Topsoil }\end{array}$ \\
\hline Physical Property & sandy & Loamy & $\begin{array}{l}\text { sandy/ } \\
\text { loamy }\end{array}$ & loamy & loamy & loamy \\
\hline $\mathrm{pH}$ & 7.01 & 5.07 & 5.15 & 5.24 & 4.97 & 5.18 \\
\hline $\mathrm{N}$ level $\mathrm{W}+\%$ & 0.062 & 0.497 & 0.238 & 0.262 & 0.179 & 0.101 \\
\hline $\begin{array}{l}\text { Phosphorus [Olsen]* } \\
\text { (ppm) }\end{array}$ & 3 & 46 & 37 & 9 & 14 & 10 \\
\hline $\begin{array}{l}\text { Potassium [Am. Acet.] } \\
\text { (meq/100g) }\end{array}$ & 0.21 & 0.43 & 0.46 & 0.23 & 0.39 & 0.30 \\
\hline $\begin{array}{l}\text { Calcium [Am. Acet.] } \\
\text { (meq/100g) }\end{array}$ & 0.92 & 5.92 & 3.66 & 1.67 & 1.35 & 3.69 \\
\hline $\begin{array}{l}\text { Magnesium [Am. } \\
\text { Acet.] (meq/100g) }\end{array}$ & 4.59 & 1.62 & 1.17 & 3.50 & 1.56 & 1.91 \\
\hline Sulphur $[M C P]^{*}(p p m)$ & 376 & 30 & 13 & 74 & 24 & 15 \\
\hline Boron $[\mathrm{CaCl} 2]^{*}(\mathrm{ppm})$ & 0.3 & 0.7 & 0.4 & 0.4 & 0.5 & 0.5 \\
\hline Copper [DTPA] (ppm) & 1.1 & 0.7 & 0.3 & 1.1 & 0.6 & 0.2 \\
\hline Iron [DTPA] (ppm) & 33 & 71 & 54 & 69 & 124 & 66 \\
\hline $\begin{array}{l}\text { Manganese [DTPA] } \\
(\mathrm{ppm})\end{array}$ & 8.7 & 25.9 & 6.2 & 13.3 & 6.9 & 4.8 \\
\hline Zinc [DTPA] (ppm) & 3.7 & 7.1 & 1.8 & 4.3 & 0.8 & 0.4 \\
\hline $\begin{array}{l}\text { Sodium }[\text { Am. Acet.] } \\
\text { (meq/100g) }\end{array}$ & 2.0 & $<0.1$ & 0.1 & 1.2 & 0.4 & 0.2 \\
\hline $\begin{array}{l}\text { Aluminum }[\mathrm{KCl}] \\
\text { (meq/100g) }\end{array}$ & 0.15 & 0.44 & 0.39 & 0.26 & 1.05 & 0.76 \\
\hline $\begin{array}{l}\text { Al base saturation } \\
(\%)\end{array}$ & 1.9 & 5.2 & 6.7 & 3.8 & 22.2 & 11.1 \\
\hline Aluminum (ppm) & 14 & 40 & 35 & 23 & 95 & 68 \\
\hline Sodium (ppm) & 449 & $<18.4$ & 25 & 285 & 87 & 37 \\
\hline Calcium (ppm) & 184 & 1184 & 732 & 334 & 270 & 738 \\
\hline Magnesium (ppm) & 551 & 194 & 140 & 420 & 187 & 229 \\
\hline Potassium (ppm) & 82 & 168 & 179 & 90 & 152 & 117 \\
\hline
\end{tabular}


Table S4. Strain symbiotic effectiveness of the 21 isolates compared with USDA1 10, CB 1809, CB564 and uninoculated control with Pongamia pinnata at 12-week growth period under glasshouse conditions.

\begin{tabular}{|c|c|c|c|c|c|c|c|c|}
\hline \multirow[t]{3}{*}{ TREATMENTS } & \multirow{2}{*}{$\begin{array}{c}\text { SHOOT } \\
\text { LENGTH }(\mathrm{cm})\end{array}$} & \multirow{2}{*}{$\begin{array}{l}\# \\
\text { OF }\end{array}$} & \multirow{2}{*}{$\begin{array}{l}\# \\
\text { OF }\end{array}$} & \multirow{2}{*}{$\begin{array}{l}\# \\
\text { OF }\end{array}$} & \multicolumn{4}{|c|}{ DRY WEIGHTS (grams) } \\
\hline & & & & & SHOOT & ROOT & NODULE & TOTAL \\
\hline & & NODES & LEAVES & NODULES & & & & PLANT \\
\hline CONTROL & $28 \pm 2$ & $5 \pm 1$ & $8 \pm 1$ & 0 & $1.26 \pm 0.2$ & $0.73 \pm 0.1$ & 0 & $2.00 \pm 0.2$ \\
\hline CB 1809 & $42 \pm 8$ & 8 & 15 & $142 \pm 9$ & $2.13 \pm 0.2$ & 0.62 & 0.21 & $2.75 \pm 0.2$ \\
\hline USDA 110 & $40 \pm 4$ & $5 \pm 1$ & $9 \pm 1$ & $81 \pm 13$ & $2.12 \pm 0.4$ & $0.70 \pm 0.1$ & 0.16 & $2.98 \pm 0.3$ \\
\hline CB 564 & $32 \pm 3$ & $6 \pm 1$ & $13 \pm 2$ & $63 \pm 24$ & $1.35 \pm 0.3$ & $0.81 \pm 0.2$ & 0.10 & $2.16 \pm 0.5$ \\
\hline PR-UQ-01 & $47 \pm 1$ & 6 & $13 \pm 1$ & $148 \pm 18$ & $2.65 \pm 0.2$ & $0.80 \pm 0.1$ & $0.28 \pm 0.1$ & $3.73 \pm 0.4$ \\
\hline PR-UQ-02 & $33 \pm 2$ & $7 \pm 1$ & $14 \pm 2$ & $71 \pm 7$ & $1.47 \pm 0.1$ & $0.99 \pm 0.2$ & 0.16 & $2.45 \pm 0.3$ \\
\hline PR-UQ-03 & $42 \pm 6$ & $6 \pm 1$ & $13 \pm 2$ & $84 \pm 19$ & $2.02 \pm 0.5$ & $0.94 \pm 0.2$ & 0.16 & $2.96 \pm 0.7$ \\
\hline PR-UQ-04 & $43 \pm 3$ & 5 & $13 \pm 2$ & $152 \pm 19$ & $2.10 \pm 0.1$ & 0.67 & 0.21 & $2.78 \pm 0.1$ \\
\hline PR-UQ-05 & $36 \pm 2$ & $5 \pm 1$ & $11 \pm 2$ & $143 \pm 29$ & $1.33 \pm 0.1$ & $0.76 \pm 0.1$ & 0.15 & $2.09 \pm 0.2$ \\
\hline PR-UQ-06 & $44 \pm 2$ & $6 \pm 1$ & $15 \pm 2$ & $99 \pm 17$ & $2.07 \pm 0.3$ & $0.70 \pm 0.1$ & 0.27 & $3.05 \pm 0.3$ \\
\hline PR-UQ-07 & $41 \pm 1$ & $6 \pm 1$ & 13 & $118 \pm 12$ & $2.12 \pm 0.2$ & $0.78 \pm 0.1$ & 0.22 & $2.98 \pm 0.1$ \\
\hline PR-UQ-08 & $42 \pm 3$ & 6 & $14 \underline{ \pm 2}$ & $127 \pm 15$ & $2.03 \pm 0.2$ & $0.91 \pm 0.1$ & 0.24 & $3.18 \pm 0.3$ \\
\hline PR-UQ-09 & $34 \pm 2$ & $6 \pm 1$ & $15 \pm 2$ & $61 \pm 26$ & $1.56 \pm 0.2$ & $1.13 \pm 0.1$ & $0.15 \pm 0.1$ & $2.69 \pm 0.2$ \\
\hline PR-UQ-10 & $38 \pm 4$ & $7 \pm 1$ & $10 \pm 2$ & $48 \pm 20$ & $1.54 \pm 0.3$ & $0.98 \pm 0.1$ & 0.09 & $2.51 \pm 0.4$ \\
\hline PR-UQ-11 & $36 \pm 2$ & $8 \pm 1$ & $16 \pm 2$ & $115 \pm 9$ & $1.70 \pm 0.3$ & $1.08 \pm 0.1$ & 0.15 & $2.77 \pm 0.3$ \\
\hline PR-UQ-12 & $28 \pm 2$ & $5 \pm 1$ & $11 \pm 2$ & $35 \pm 15$ & $0.98 \pm 0.1$ & 0.76 & 0.05 & $1.74 \pm 0.2$ \\
\hline PR-UQ-13 & $39 \pm 1$ & $7 \pm 1$ & $15 \pm 1$ & $50 \pm 8$ & $2.05 \pm 0.2$ & 1.19 & 0.13 & $3.24 \pm 0.2$ \\
\hline PR-UQ-14 & $39 \pm 2$ & $8 \pm 1$ & $16 \pm 2$ & $66 \pm 6$ & $1.97 \pm 0.2$ & 1.05 & 0.14 & $3.02 \pm 0.2$ \\
\hline PR-UQ-15 & $41 \pm 3$ & 7 & 16 & $81 \pm 16$ & $1.79 \pm 0.2$ & $0.82 \pm 0.1$ & $0.16 \pm 0.1$ & $2.61 \pm 0.2$ \\
\hline PR-UQ-16 & $29 \pm 2$ & $6 \pm 1$ & $10 \pm 1$ & $25 \pm 12$ & $0.81 \pm 0.2$ & $0.46 \pm 0.2$ & 0.05 & $1.27 \pm 0.4$ \\
\hline PR-UQ-17 & $34 \pm 4$ & 6 & $10 \pm 1$ & $25 \pm 15$ & $0.83 \pm 0.2$ & 0.23 & 0.04 & $1.06 \pm 0.2$ \\
\hline PR-UQ-18 & $30 \pm 3$ & $6 \pm 1$ & $13 \pm 1$ & $19 \pm 12$ & $0.93 \pm 0.2$ & $0.35 \pm 0.1$ & 0.03 & $1.28 \pm 0.3$ \\
\hline PR-UQ-19 & $31 \pm 3$ & 7 & $11 \pm 1$ & $44 \pm 9$ & $1.18 \pm 0.2$ & $0.71 \pm 0.1$ & 0.09 & $1.89 \pm 0.4$ \\
\hline PR-UQ-20 & $29 \pm 4$ & $6 \pm 1$ & $11 \pm 1$ & $54 \pm 6$ & $0.85 \pm 0.2$ & $0.44 \pm 0.1$ & 0.07 & $1.29 \pm 0.3$ \\
\hline PR-UQ-21 & $30 \pm 4$ & $6 \pm 1$ & $10 \pm 1$ & $32 \pm 11$ & $0.83 \pm 0.1$ & $0.37 \pm 0.1$ & 0.04 & $1.20 \pm 0.2$ \\
\hline
\end{tabular}

Shown are the mean values (with SE) for all the five replicates used in each treatment. Legend: yellow highlights - high values; blue highlights - low values. 
Table S6. Characteristics of PR-UQ-03 and PR-UQ-05 based on various parameters.

\begin{tabular}{lll}
\hline Parameters & PR-UQ-03 & PR-UQ-05 \\
\hline Origin & Pongamia nodule, Botanical Gardens, & Pongamia nodule, Botanical Gardens, Mt. \\
& Mt. Coot-tha, Brisbane, Australia & Coot-tha, Brisbane, Australia \\
Colony morphology & $2-3 \mathrm{~mm}$ diam; white; high convex; & $3-4 \mathrm{~mm}$ diam; white but later observed to \\
& slimy & $\begin{array}{l}\text { have red center in longer incubation; high } \\
\text { convex; excessively slimy }\end{array}$ \\
& & $\begin{array}{l}\text { Positive } \\
\text { Nodulation }\end{array}$ \\
$\mathrm{pH}$ & 7 & 7 \\
NaCl tolerance/salinity & $0.1-0.5 \%$ & $0.1-0.5 \%$ \\
Temperature & $22-28^{\circ} \mathrm{C}$ & $22-28^{\circ} \mathrm{C}$ \\
Carbon utilisation & Mannitol & Mannitol \\
Antibiotic resistance & Resistant to AMP, SPEC \& TET & Resistant to AMP, SPEC \& TET \\
Turbidity in YM broth & $\geq 72$ hours & $<48$ hours \\
Incubation & 3 days & $<3$ days \\
\hline
\end{tabular}

Figure S1. Pongamia seedlings at different treatments. All pongamia plants with both cotyledons removed (OCOT) had consistent lowest shoot length, shoot dry weight, nodule number and nodule dry weight (yellow). Uninoculated plants without nutrients but both cotyledons intact (2COT) grew as well as those with nutrients implicating that cotyledons supply the seedling with nutrients for a considerable period of early seedling growth.

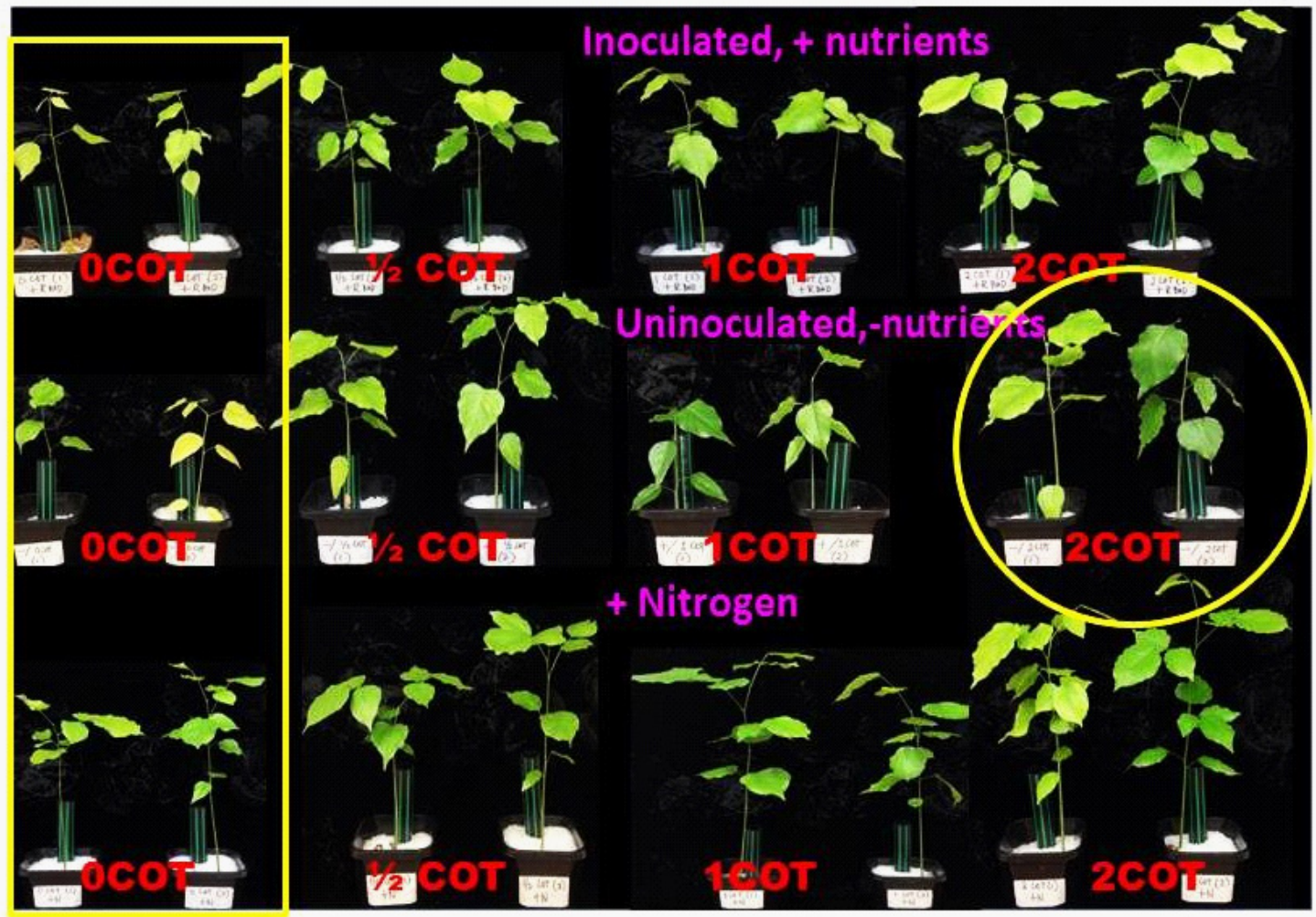


Figure S2. Amplified 16S rDNA $(1,250 \mathrm{bp})$ of the four best rhizobia isolates: Lane $1=$ Negative Control; Lanes 2 and 3 = PR-UQ-01; Lanes 4 and $5=$ PR-UQ-03; Lanes 6 and $7=\mathrm{PR}-\mathrm{UQ}-04$; and, Lanes 8 and $9=\mathrm{PR}-\mathrm{UQ}-05$. (blue arrows indicate the predicted PCR product).

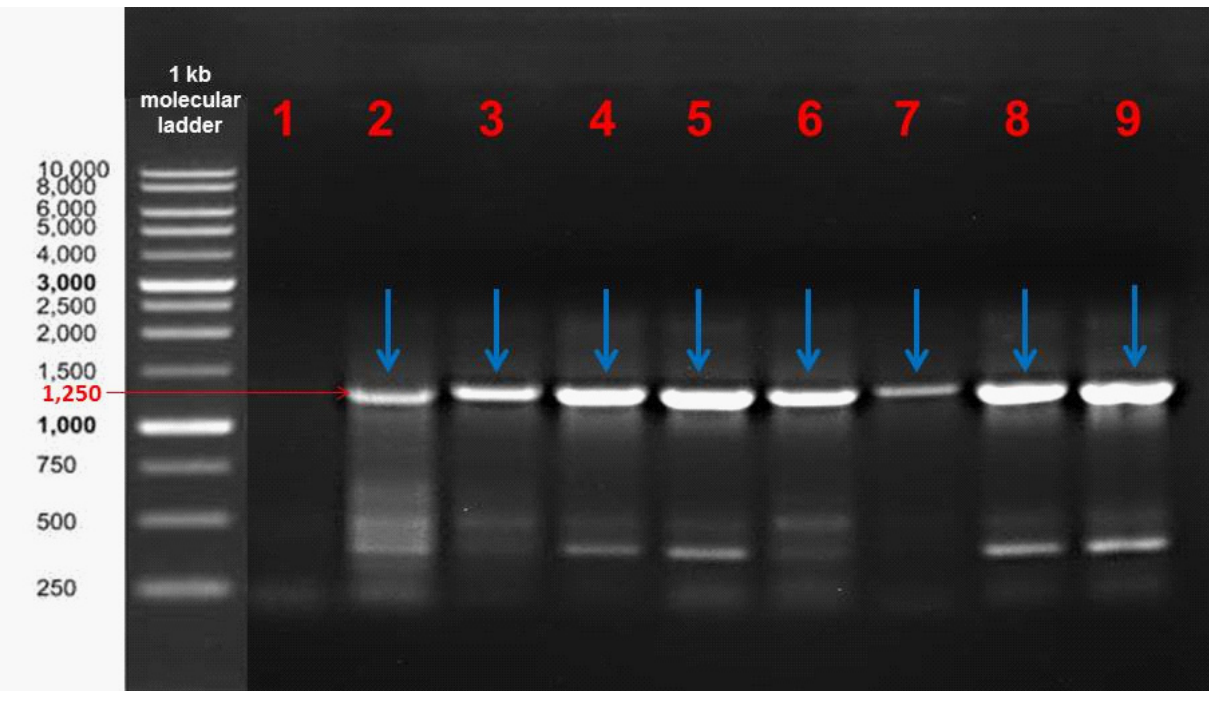

